\title{
The localisation of advertising print media as a multimodal process
}

\section{Hiippala, Tuomo}

Palgrave Macmillan

2012

Hiippala , T 2012 , ' The localisation of advertising print media as a multimodal process ' , in W L Bowcher (ed.) , Multimodal Texts from Around the World: Linguistic and Cultural Insights Palgrave Macmillan, London, pp. 97-122.

http://hdl.handle.net/10138/28410

Downloaded from Helda, University of Helsinki institutional repository.

This is an electronic reprint of the original article.

This reprint may differ from the original in pagination and typographic detail.

Please cite the original version. 
NB! Author's version: do not cite!

Use the following reference instead: Hiippala, T. (2012) The localisation of advertising print media as a multimodal process In W.L.

Bowcher (ed.) Multimodal Texts from Around the World: Linguistic and Cultural Insights. London: Palgrave McMillan. 97-122. 


\title{
The localisation of advertising print media as a multimodal process
}

\author{
Tuomo Hiippala \\ Department of Modern Languages \\ University of Helsinki
}

\section{Introduction}

The concept of localisation is typically associated with the field of information technology and software development, and involves describing the process of translating a product and its documentation and verifying the translation and accounting for any cultural factors that might be related to the use of the product. Localisation has emerged as a result of the globalised markets and business, where products are first developed with international markets in mind, and then adapted to countryspecific markets where they are intended to be sold. Esselink (2000, p. 3) quotes a definition from the Localisation Industry Standards Association (LISA), which describes the process of localisation and introduces the concept of a locale:

Localisation involves taking a product and making it linguistically and culturally appropriate to the target locale (country/region and language) where it will be used and sold.

The LISA definition focuses on the practical aspects of localisation, emphasising the role of language in the process. This reflects the status of language as the dominant semiotic resource in society. However, other semiotic resources, such as layout, colour and typography, may also be used to communicate cultural values and should thus be acknowledged when making a product culturally appropriate. Kostelnick \& Hassett (2003, p. 92) have pointed out that cultures define powerful and often well-entrenched visual discourse communities, citing examples from visual design: writing direction, page layout and size, typography and the meanings carried by non-textual elements such as images and symbols. These issues have been frequently discussed in multimodal research and therefore constitute an area where theories of multimodal meaning-making can contribute to the process of localisation (Bateman et al. 2007, Machin 2004, Stöckl 2005, van Leeuwen 2005). 
This chapter takes a step forward by extending the concept of localisation to print media advertising by using the established theories of multimodality to analyse the localisation process in tourist brochures produced by the city of Helsinki for two locales: Finland and the English-speaking countries. The study aims to bridge the gap between multimodal theories and their practical application in the field of localisation, thus benefiting both academic and professional communities. The main aims of the study may be summed up in two points:

1. To redefine localisation as a multimodal process, where semiotic resources are adapted to culture-specific conventions.

2. To extend the concept of localisation from its traditional domain of information technology and design to other contexts, and to show the benefits of multimodal localisation in cross-cultural communication.

The chapter begins with a discussion of tourist brochures, focusing on their production, content and functions, followed by a review of relevant research on multimodality and the theoretical framework of the study. It then presents the material and the methods of the study, followed by an analysis that presents and discusses some of the examples from the collected data. The chapter concludes with a discussion of the results and their implications.

\section{Tourist brochures: production, content and functions}

This section discusses three aspects of tourist brochures and their implications to the localisation process. It seeks to highlight the semiotic resources and media that may be used to transmit cultural values and which are therefore perceived as relevant to the process. Beginning with production, the section discusses the choices made by the producers and designers before moving on to discuss the content and the overall functions of tourist brochures.

\subsection{Production}

Kress \& van Leeuwen (2001, p. 66) define production as the communicative use of both media and material. Tourist brochures may be classified as belonging to a large group of products known as print media, whose members are characterised by the use of printing techniques on various forms of physical media. The use of print media does not only set constraints on the use of language, image, and combinations thereof and their organisation, but also involves making choices in the materials used: their size, shape, surface, binding and so on. These choices 
are affected by the intended use of the tourist brochures, which are generally expected to be small-sized and easily carried around. This feature limits the space available and the variety of semiotic resources that may be utilised. Although production is only one of the four domains defined by Kress \& van Leeuwen (2001), the others being design, discourse and distribution, the range of choices available in production and the semiotic resources shows their complex interrelatedness and how the outcome of the process is affected by many factors, all of which may differ between cultures. Furthermore, the interaction between producers and consumers establishes the framework for classifying the products of the meaningmaking process:

[Meaning] results from human engagement with the world, and the resources we use in articulating and interpreting meaning comprise both semiotic modes and semiotic media. It is the effect of a particular kind of semiotic/cognitive/affective work: the integration of an individual of a semiotic element (or a complex of semiotic elements) into their already existing and constantly transformed systems of classification. (Kress \& van Leeuwen 2001, p. 68)

The tourist brochure, as a semiotic artefact, is therefore a product of both verbal and visual choices arising from the interaction between articulation and interpretation, which are used to place it into the systems of classification. These systems are used to distinguish one semiotic artefact from another. In print media, the deployment and use of verbal and visual elements can be used to identify artefacts such as movie posters or postcards, or more closely related artefacts such as tourist guides.

Deep cultural patterns may be found in these seemingly mundane artefacts, as shown by (Martinec 2003) in a contrastive study of Japanese and English cooking recipes. The analysis showed that the Japanese texts used colour and typography to emphasise the sequential structure of the text, while also utilising more images than their English counterparts. In some cases, the English texts showed similar features, signalling a possible turn towards increased visuality in this particular type of procedural text. Kostelnick (1995, p. 182) points out that documents have deep cultural tracks in both verbal and visual content, arguing that although language is considered the dominant carrier of cultural information and values, the importance of visual communication is increasing in this aspect. He also suggests that the cultural adaptation of visual communication can be approached from two directions: global and culture-focused. Table 1 shows an overview of these two approaches from the perspectives of both the designer and the user.

The work of Martinec and Kostelnick suggests a need for paying increased attention to the localisation of visual elements in a multimodal text, because they are also used to communicate cultural values. In this aspect, the contributions made 
Table 1: Global and culture-focused approaches to visual communication

\begin{tabular}{|c|c|c|}
\hline & Global & Culture-Focused \\
\hline $\begin{array}{l}\text { Design assump- } \\
\text { tions }\end{array}$ & $\begin{array}{l}\text { Images can be simplified } \\
\text { and homogenized to make } \\
\text { them accessible to diverse } \\
\text { audiences. }\end{array}$ & $\begin{array}{l}\text { Something is lost in stream- } \\
\text { lining images, or the generic } \\
\text { form itself carries cultural } \\
\text { baggage. }\end{array}$ \\
\hline Design goals & $\begin{array}{l}\text { Systematization, con- } \\
\text { ventions and standards; } \\
\text { generic forms erase cultural } \\
\text { differences. }\end{array}$ & $\begin{array}{l}\text { Design must be adapted } \\
\text { to cultural context, partly } \\
\text { by invoking familiar conven- } \\
\text { tions. }\end{array}$ \\
\hline $\begin{array}{l}\text { Modes of recep- } \\
\text { tion }\end{array}$ & $\begin{array}{l}\text { Perception and legibility are } \\
\text { key; universality of vi- } \\
\text { sual language is certified by } \\
\text { perceptual psychology (e.g., } \\
\text { gestalt) and empirical re- } \\
\text { search. }\end{array}$ & $\begin{array}{l}\text { User's interpretations cre- } \\
\text { ate meaning; visual lan- } \\
\text { guage is learned, experi- } \\
\text { enced; testing with target } \\
\text { audiences can enhance the } \\
\text { adaptation. }\end{array}$ \\
\hline
\end{tabular}

Source: Kostelnick (1995, p. 182)

in this volume to cultural and linguistic insights into multimodality seem to be touching upon an increasingly important aspect in multimodal research. However, language is still the top priority in localisation, although texts are shifting towards multimodal meaning-making. Several reasons for the lower priority of visual elements in the localisation process may be postulated. Firstly, the production cycle may not allow enough time and resources for localisation across the full range of semiotic resources, thus producers opt for the least time- and resource-consuming choice of linguistic translation. Secondly, there may not be a sufficient amount of research available to convince the producers to invest in multimodal localisation and to support the design choices needed during the process of adopting an artefact from one locale to another. For these reasons, the global approach to cultural adoption seems to be dominant at the moment; a trend that is also observed by Machin (2004) in his work on the role of image banks in corporate visual communication. The global approach assumes and promotes shared cultural values that result in a reduced need for visual localisation. This is particularly interesting from the perspective of localising tourist brochures, as the image banks attempt to codify the visual in descriptive advertising texts, although high-level codification of visuality has been traditionally attributed to specific discourse communities such as engineering and science (Kostelnick \& Hassett 2003, p. 144). For this reason, the content of tourist brochures and its intended functions requires a closer analysis. 


\subsection{Content}

The content of a tourist brochure varies according to its intended audience, which is reflected in its language and visual appearance. However, the content can be generally characterised by using Barthes concept of myth, as the advertising content often repeats generally accepted truths that rarely have real-life counterparts. Barthes (1957/1973, p. 137-8) suggests that mythical concepts are construed of signs, which produce social constructions that are perceived as facts. In a myth, a sign acts as a signifier, coupled with a signified formed by a group of signs with an ideological load, which replaces the original signified. Myths have no fixed position: new myths emerge and old ones disappear or are renewed. For instance, Barthes description of the French view on 'Chineseness' (1957/1973, p. 144) as a mix of bells, rickshaws and opium dens is likely to have evolved into something else in the modern world.

Tourist brochures often employ myths to persuade the reader and to create a positive image of the city as a tourist destination. Content that might work against this goal is excluded; new shopping centres, designer boutiques and historical landmarks are presented instead of low-income housing and social problems. Myths are used to assign a particular value to a location, such as the Lutheran Cathedral as the symbol of Helsinki, or the 'design district', formed by a group of shops and boutiques identified by a 'Design District Helsinki' sticker on their doors and advertised as representing cutting-edge Finnish design. In order to create this type of advertising content, the concept of provenance, as defined by Kress \& van Leeuwen (2001, p. 72), is often employed:

... 'mythical' signifieds are 'imported' from some other domain (some other place, time, social group, culture) to signify a complex of ideas and values which are associated with that 'other' domain by those who do the importing.

An example of provenance in the Helsinki tourist brochures is the use of an advertising slogan, 'Daughter of the Baltic', which was used between the 1960s and 1980s to advertise Helsinki as the capital of a neutral country acting as a meeting point between the West and the East (Hiippala 2007). The slogan originated from the name of a trilogy by Maila Talvio, a writer during the 1930s and known for her anti-Russian and conservative opinions (Laitinen 1998, p. 123-4). Its use in the city's tourist brochures between the 1960s and 1980s is ironic considering the considerable influence the Soviet Union wielded over Finlands foreign and domestic policy at that time. In current advertising, the image of the city has been reinvented and the influence of Eastern European cultures is emphasised, using generalised or obscure slogans such as 'Discover Helsinki', 'Sense Helsinki', and 'Bohemian Nordic Oddity'. 
Myths are realised using multiple semiotic resources in the tourist brochures, advertising the city and suggesting activities to the reader: the brochures adopt both persuasive language and visuals to achieve these goals. Cultures may have different linguistic and visual conventions in advertising, which should be taken into consideration in localisation. This is not necessarily considered important and is subsequently only taken into account when the 'cultural gap' gets too wide: a good example is adapting Western products and advertising to Middle Eastern markets, where the code of visual communication is strictly defined by cultural factors relating to religion. Nevertheless, researching the semiotic patterns of the target locale may result in more effective and functional communication, not only in the case of advertising content, but also for highly codified informational content in maps.

\subsection{Functions}

Print media artefacts typically fulfil a function in social interaction: they emerge and evolve according to need. Artefacts such as direct mail advertisements, invoices, and greeting cards exemplify the wide range of artefacts in daily use. The function of a tourist brochure is to advertise a destination and provide the readers with information that enables them to realise the activities suggested in the advertising content. In a wider perspective, Culler (1988) suggests that tourist brochures play an important role in the discourse of tourism by acting as 'markers'. Markers, such as souvenirs, brochures, and postcards, are used to establish the significance of a location as a tourist attraction. In particular, Culler (1988, p. 159) refers to tourist brochures as a special type of mobile marker:

... mobile markers, such as pamphlets and brochures, designed to draw people to the site, give information at the site, and serve as souvenirs or representations off the site.

According to Culler's definition, tourist brochures are multifunctional, performing the tasks the designers intended them to do (to advertise and inform), but they may also serve as mementoes of a visit to a destination. It will be suggested that these functions can be divided into two categories: primary and secondary. The primary functions, originating from the design and production, are the main focus of localisation, whereas the secondary functions of an artefact are irrelevant in this context. For this reason, the localisation process needs to establish how a culture uses semiotic resources to fulfil the primary functions of an artefact. This can be achieved by using multimodal analysis to describe the artefacts and their structures. Section 3 reviews the significant theoretical frameworks available for multimodal analysis and evaluates their applicability in the localisation process. 


\section{Visual communication and multimodal analy- sis in localisation}

The following section presents the various theoretical frameworks that have been developed for describing visual communication and multimodal meaning-making. Beginning with the work of Kostelnick \& Hassett (2003), the section outlines some of the more abstract aspects of visual communication in the form of conventions, followed by an evaluation of the presently available theories of multimodality and their applications in localisation. The section aims to formulate a theoretical framework that enables the description of the choices made in the design and localisation process, and the possible reasons behind these choices.

\subsection{Visual communication and conventions}

Kostelnick \& Hassett (2003) present a framework for describing the dynamics of visual communication based on the notion of design conventions. According to Kostelnick \& Hassett, conventions emerge and are shaped in the social interaction between the designers and the readers. In this cycle, the conventions are constantly negotiated as the designers produce new designs, which may draw on established conventions, mix conventions from different contexts, or break conventions and introduce completely novel designs to the readers. However, the readers have the power to embrace the new conventions or to reject them, thus influencing the cycle. Upon observation from the present point in time, conventions may appear as static and highly codified due to naturalisation, but in fact the conventions are subject to constant change and therefore evolve over time. Kostelnick \& Hassett (2003,
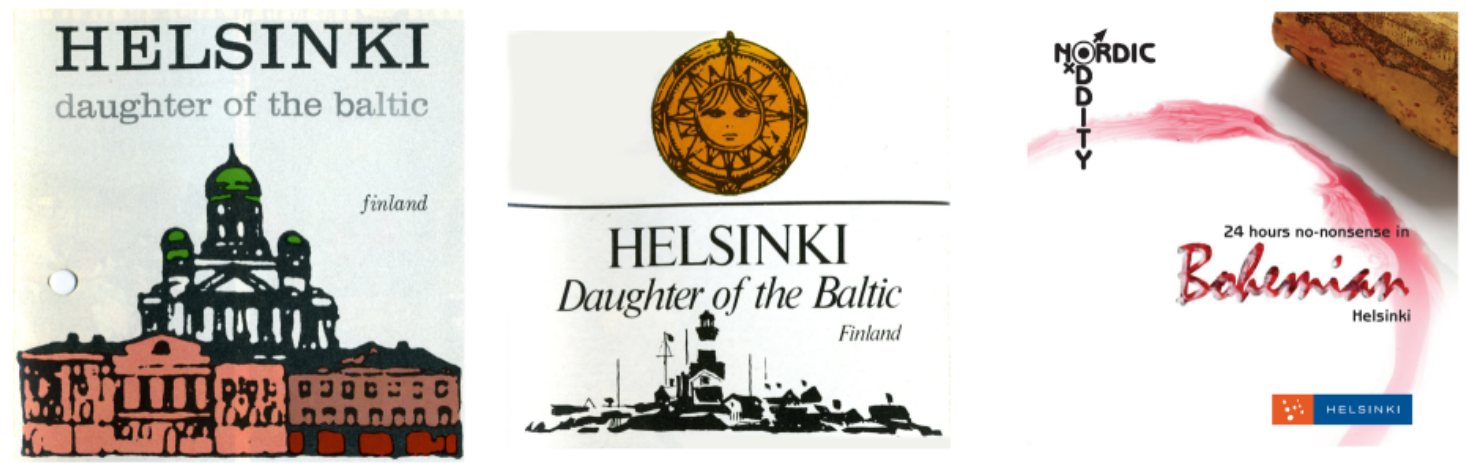

Figure 1: Design conventions in tourist brochures: 1964, 1977 and 2008

p. 16) describe conventions on two levels: micro and macro. The reach and range of conventions are illustrated in Figure 1, which shows headers from brochures published in 1964 and 1977, and a complete cover from 2008. The examples from 
1964 and 1977 show a microlevel typographic convention affecting the headers: typographical variation is used to distinguish between the header and the slogan underneath it. In contrast, the example from 2008 does not only illustrate the same microlevel convention, but also a macrolevel convention in the form of a cover page, which print media artefacts like tourist brochures are expected to have. Moreover, all three examples in Figure 1 show not only the extent and reach of conventions in design, but also represent the development of design aesthetics over time, reflected in the use of typography, image and colour.

The main contribution to localisation from Kostelnick \& Hassett (2003, p. 92) comes in the form of an important observation that 'designers and readers shape visual language through the cultural lens of their own experiences and values', which emphasises the influence of cultural factors in shaping design conventions. Citing examples ranging from typography to writing direction, Kostelnick \& Hassett (2003, p. 92-3) argue that despite the fact that some conventions have crossed over from one discourse community to another on a cultural level, many culturespecific conventions persist. Localisation obviously aims to account for major macrolevel conventions such as writing direction, but culturally valued microlevel conventions are likely to be more easily ignored. Again, this may result from a lack of research to back up design choices during localisation, but also because microlevel localisation is seen as interfering with the work of the designer. The development of localisation as a multimodal process therefore requires bridging the gap between cultural studies and visual communication, and combining them with multimodal analytical frameworks. Cultural studies may be used to describe the differences between cultures of the source and target locale, while multimodal analysis may be used to show how the culture-specific conventions are realised using various semiotic resources. The multimodal frameworks available for this task are described in the following subsection.

\subsection{Multimodal analysis: theoretical frameworks}

This subsection presents several theoretical frameworks and their applications in the analysis of both print and digital media in multimodal cross-cultural contexts. The approaches may be roughly divided into two categories: the integrative approaches that seek to describe corresponding structures across semiotic resources and the empirical approaches that emphasise observation and corpora in multimodal analysis. The subsection begins with the integrative approaches and concludes with the empirical approaches. 


\subsubsection{The integrative approaches}

The works of O'Toole (1994) and Kress \& van Leeuwen (1996) are often regarded as the pioneering works in multimodal research, a status rightfully warranted to them for beginning the discussion on multimodality. Both works have their roots in Systemic Functional Linguistics (hereafter SFL), drawing on Halliday's (1978) ideas on the metafunctionality of language, which were extended to other forms of semiosis, such as photography, graphic design, sculpture, architecture and painting. O'Halloran (2008, p. 444) sums up the principle of metafunctionality as follows:

The metafunctional principle is the principle that semiotic resources simultaneously provide the tools for constructing ideational meaning (i.e. experiential meaning and logical relations) and for enacting social relations (i.e. interpersonal meaning). These metafunctions are enabled through the organisation of discourse, which is the textual metafunction of semiosis.

The metafunctional principle is an essential component of the integrative approaches, acting as a cross-semiotic theoretical concept that provides a link between the semiotic resources. This is one of the main strengths of the integrative approaches, as it allows a close description of language and other semiotic resources. The approach has been applied to a wide range of material, all of which cannot be covered in this chapter: examples can be found in O'Halloran (2004, 2005), Ventola et al. (2004), Jones \& Ventola (2008), and Ventola \& Guijarro (2009), while Kaltenbacher (2004) presents a formidable overview of multimodal research. However, cross-cultural analyses with comparative methods have been relatively rare, although the potential for applications in the field of localisation exists. The remaining part of this subsection is dedicated to reviewing particularly interesting research from this perspective.

Hopearuoho \& Ventola (2009) present an analysis of car advertisements in both print and digital media using a theoretical framework based on the metafunctional principle. The authors adopt a perspective contrasting globalisation and localisation, pointing out the need of the producers to negotiate between the global advertising strategies and providing some local flair to the marketing in different countries. In print media ads, localisation is achieved by introducing new ideational meanings using both language and image: the advertisement is bound to time and place with a logo of a sports event sponsored by the manufacturer and the national flag of Finland (Hopearuoho \& Ventola 2009, p. 193-4). According to the authors, photography is not localised, suggesting it follows the trend proposed by Machin (2004), where global photography replaces local work. From the perspective of this chapter, it seems that the capability to segment the multimodal artefact into analytical units is necessary for contrastive studies in order to 
identify the elements contributing to localisation. Integrative approaches such as Systemic Functional-Multimodal Discourse Analysis (SF-MDA) (see O'Halloran 2008) provide segmentation using a rank scale formed by compositional layers held together by the relationship of 'is a part of' (Halliday \& Matthiessen 2004, p. 20): the ranks in language (clause complex / clause / word group or a phrase / word) correspond with the ranks in visual images (scene / episode / figure / part), resulting in intersemiosis across the resources (O'Halloran 2008, p. 456). In the same tradition, Cheong (2004) suggests an approach based on a more abstract level, proposing a multimodal generic structure for print advertisements that includes both obligatory and optional elements, which could be used for studying culture-specific generic structures in multimodal artefacts.

The main contribution of the integrative approaches may come in the form of detailed analyses, which can be used to contrast multimodal meaning-making processes across cultures. However, credible analyses require the support of volume if the goal is to identify design conventions. O'Halloran (2008, p. 445) points out that one of the challenges facing multimodal analysis based on SFL is the development of software applications to aid in the analysis and creation of multimodal corpora, which is undoubtedly true if the amount and scope of multimodal analyses are to increase. However, the application of the metafunctional principle itself has been criticised, particularly in connection with the textual metafunction and its application in the work of Kress \& van Leeuwen (1996). Criticism presented in Bateman et al. (2004, p. 66-7), Bateman (2008, p. 42-6) and Thomas (2009a) warrant caution in some aspects related to localisation; especially with those associated with culture-specific design conventions and the overall organisation of visual and verbal elements in a layout. Nevertheless, the highly detailed descriptive capability of the integrative approaches is a potent tool when employed critically for the purpose of describing how the semiotic resources are used, instead of producing 'impressionistic interpretative' analyses (Bateman et al. 2004, p. 67).

\subsubsection{The empirical approaches}

In contrast to the integrative approaches to multimodality, the empirical approaches do not adopt a theoretical concept (such as the metafunctional principle) as a starting point for studying the interaction between semiotic resources, but instead aim to base any hypotheses on observation and the study of multimodal corpora. This inevitably affects the research focus and directs it towards the large-scale organisation of meanings and the resulting interaction. One of the first frameworks of this type was produced by the Genre and Multimodality (hereafter $\mathrm{GeM}$ ) research project, which was conducted at the universities of Stirling and Bremen between 1999 and 2002, resulting in the creation of a multi-layered analytical framework with an XML-based annotation scheme for creating multimodal 
corpora. The GeM model adopts the notion of genre as the basis for the study

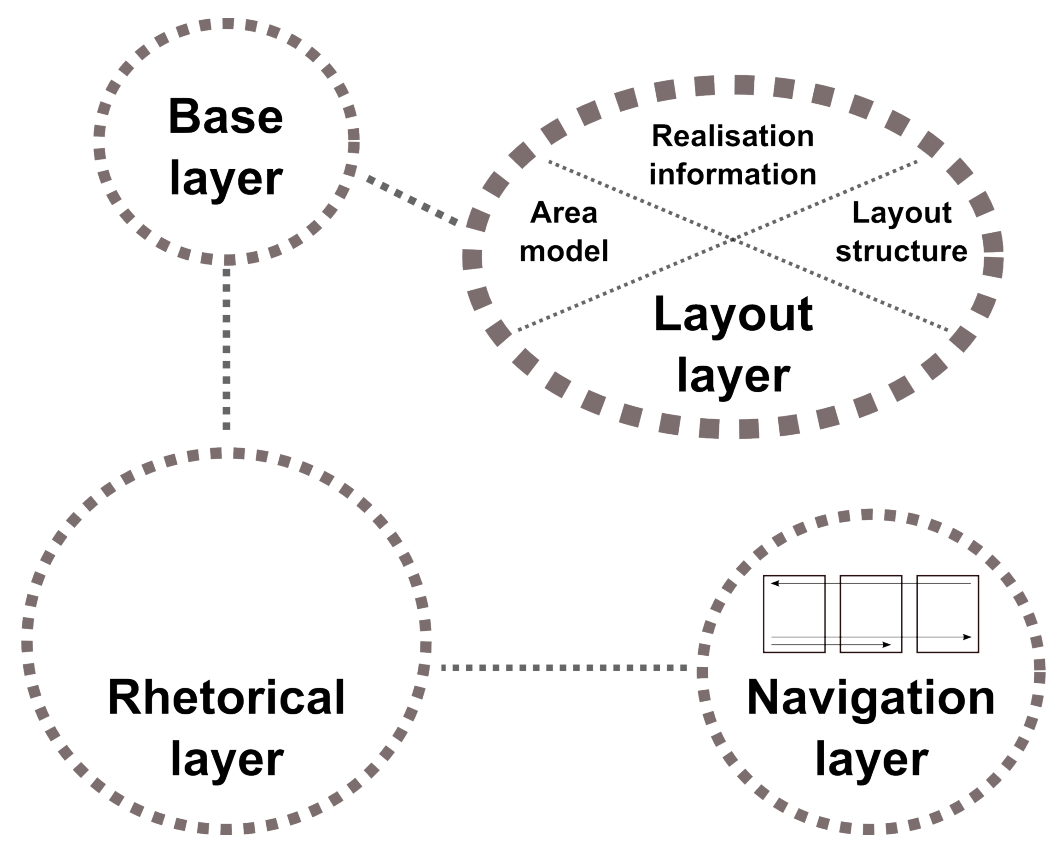

Figure 2: The cross-referencing of XML annotation in the GeM model

of multimodal documents, providing multiple analytical layers that can be used to define parameters for a genre 'space' (Delin et al. 2003, p. 54). The analytical layers are described in detail in Table 2 and their cross-referencing in the XML annotation is presented in Figure 2. Bateman (2008, p. 10-11) argues that genre is a well-established starting point for comparing multimodal artefacts: the concept is often used in multimodal research (although its definition has remained vague), and the genre space offers flexibility as opposed to rigid categorisation, thus allowing a dynamic account capable of describing changing design conventions. Finally, the multimodal definition of genre acknowledges the role of materiality: print and digital media interact with the reader in different ways. If cultural values are communicated both linguistically and visually, their influence should be reflected in the notion of multimodal genre as well. For instance, the genre structures shaping the content and form of a multimodal artefact may exhibit differences between cultures in typography, photography, colour use and so on. The framework provided by the GeM model can be used to identify possible cultural differences in the various analytical layers. Furthermore, it also allows the comparison of localisation by contrasting the differences between the source and the target artefacts. Thomas (2009b) applied the GeM framework to the analysis of localisation in the packaging design of fast-moving consumer goods (toothpaste, shampoo, etc.) in the United Kingdom and Taiwan. Although dealing with relatively uncommon material in 
Table 2: The layers of the GeM model

\begin{tabular}{|c|c|c|}
\hline Layer name & Descriptive function & $\begin{array}{l}\text { Analytical unit and ex- } \\
\text { amples }\end{array}$ \\
\hline Base layer & $\begin{array}{l}\text { Provides a list of base units } \\
\text { that may be analysed as a } \\
\text { part of other layers. }\end{array}$ & $\begin{array}{l}\text { Base units: sentences, } \\
\text { headings, drawings, figures, } \\
\text { photos, captions, list items, } \\
\text { etc. }\end{array}$ \\
\hline Layout layer & $\begin{array}{l}\text { Groups the base units to- } \\
\text { gether based on similar } \\
\text { properties in the three do- } \\
\text { mains below. }\end{array}$ & $\begin{array}{l}\text { Layout units: paragraphs, } \\
\text { headings, drawings, figures, } \\
\text { photos, captions, list items, } \\
\text { etc. }\end{array}$ \\
\hline Structure & $\begin{array}{l}\text { The hierarchical structure } \\
\text { between layout units. }\end{array}$ & \\
\hline Area model & $\begin{array}{l}\text { The placement of layout } \\
\text { units in a layout. }\end{array}$ & \\
\hline Realisation & $\begin{array}{l}\text { Typographical or visual fea- } \\
\text { tures of layout units. }\end{array}$ & \\
\hline Rhetorical layer & $\begin{array}{l}\text { Describes the rhetorical } \\
\text { relations holding between } \\
\text { the identified rhetorical } \\
\text { segments. }\end{array}$ & $\begin{array}{l}\text { Rhetorical segments: } \\
\text { base units with rhetorical } \\
\text { functions. }\end{array}$ \\
\hline Navigational layer & $\begin{array}{l}\text { Describes the navigational } \\
\text { structure by defining point- } \\
\text { ers, entries and indices. }\end{array}$ & $\begin{array}{l}\text { Pointers, entries and in- } \\
\text { dices: base units and lay- } \\
\text { out units with navigation } \\
\text { functions. }\end{array}$ \\
\hline
\end{tabular}

Sources: Bateman (2008, p. 111-28) and Henschel (2003, p. 20-22)

multimodal research, Thomas' (2009b, p. 319-20) analysis showed differences in packaging design. For example, Taiwanese designs preferred to realise the brand identity of a product using image, whereas typographic variation was more common in the packages designed for the UK market (Thomas 2009b, p. 287-93). These observations may indicate culture-specific design conventions. In addition, Thomas (2009b) employed optical character recognition software to partially automate the annotation procedure and developed a multimodal concordancer for investigating GeM-annotated multimodal corpora (Thomas 2007). The GeM model annotation schema, based on XML markup language, shows promising results in the study of cross-cultural communication: the systematic framework is suited for comparative studies and may be extended by defining additional analytical layers to annotate and describe specific phenomena in the analysed multimodal artefacts. To sum 
up, the GeM model appears to provide a means of identifying and comparing the localised elements in tourist brochures, thus complementing the previous research on similar multimodal artefacts within the integrative frameworks. Section 4 describes how the model will be used for the purpose of comparing the localisation of the Helsinki tourist brochures.

\section{Material and methods}

The material for this study consists of four tourist brochures produced by the city of Helsinki, Finland (see Table 3). This limited sample of tourist brochures, published in Finnish and English, represents contemporary tourist brochure design and localisation. Both source (Finnish) and target (English) locales may be considered to belong to the Western cultural sphere; unfortunately no examples of other locales with alternate writing directions were available for a comparison of layout designs after localisation.

Table 3: List of brochures

\begin{tabular}{lll}
\hline Finnish title & English title & Publication year \\
\hline Suomenlinnan & merilinnoi- & Suomenlinna \\
tus & Fortress & 2001 \\
Kesä-Helsinki & Summer-Helsinki & 2002 \\
Talvi-Helsinki & Winter Helsinki & 2003 \\
Helsinki on sinun & Helsinki Your Way & 2006 \\
\hline
\end{tabular}

The method of the study is based on an application of the GeM model, presented in Subsection 3.2.2, which is used to identify and describe variation across the descriptive layers of the model in the two locales. The application of the model is limited and exploratory, not a full-scale corpus study. More precisely, the model is used for critiquing the design and localisation of multimodal artefacts (cf. Delin \& Bateman 2002). The example analyses aim to cover all of the descriptive layers and comment on their role in localisation and on any challenges that may be encountered during the process. Furthermore, the analysis attempts to integrate the views of Kostelnick \& Hassett (2003) on visual communication to provide explanations and commentary on some of the design solutions implemented in localising the artefact. 


\section{Analysis}

The analysis is divided into four subsections, each of them covering one brochure and focusing on a particular aspect of the GeM model and its application in analysing localisation. Beginning with the base unit and layout variation in Suomenlinna Maritime Fortress (2001), the analysis continues with the consequences of rigid layout design in localisation, as exemplified in Summer-Helsinki (2002). Rhetorical structures are discussed in connection with Winter Helsinki (2003), while the final subsection focuses on the role of navigation structures in the localisation of Helsinki Your Way (2006).

\subsection{Suomenlinna Maritime Fortress (2001)}

The oldest brochure in the material, Suomenlinna Maritime Fortress (2001), promotes the fortress island of Suomenlinna as a tourist destination. Suomenlinna is a designated UNESCO World Heritage site. Its status as such is represented by the logo consisting of a roundel with a tilted square inside (see Figure 3), located in the bottom part of the brochures back cover. Logos, like this one, may carry a high symbolic value. They are also highly codified for international use, but may also possess local variants, as exemplified by the multilingual UNESCO logo, which includes both the Finnish 'maailmanperintö' and the English equivalent of 'world heritage'. Kostelnick \& Hassett (2003, p. 115) assign the following functions to a logo and define the factors constraining its use:

A logo reflects the collective ethos and visual identity of the organisation it represents; legal factors constrain the logos designers from replicating another organisations trademark or symbol (or vice versa); technology has to enable its efficient reproduction for all of its uses.

In the GeM model, logos are treated as single base units (see Table 2); by introducing a single visual element, the designer may signal affiliation with an organisation or provide additional information. Figure 3 shows two base units in the English brochure, which are absent from its Finnish counterpart: the FECTO logo (Federation of European Cities Tourist Offices) and the coat of arms of Helsinki. In the Finnish brochure, the FECTO logo is replaced by the logo of Suomenlinna. The inclusion of the FECTO logo may be influenced by legal factors: the member cities may have to include the logo in their international publications, however, it is likely to make little difference to the typical user of the brochure. It appears that although highly codified symbols such as logos and coats of arms may undergo limited localisation, they may also be included or excluded in the process.

Localisation may also spread or correct flawed designs as a result of carelessness in creating the source artefact, as exemplified by a map legend in the Suomenlinna 


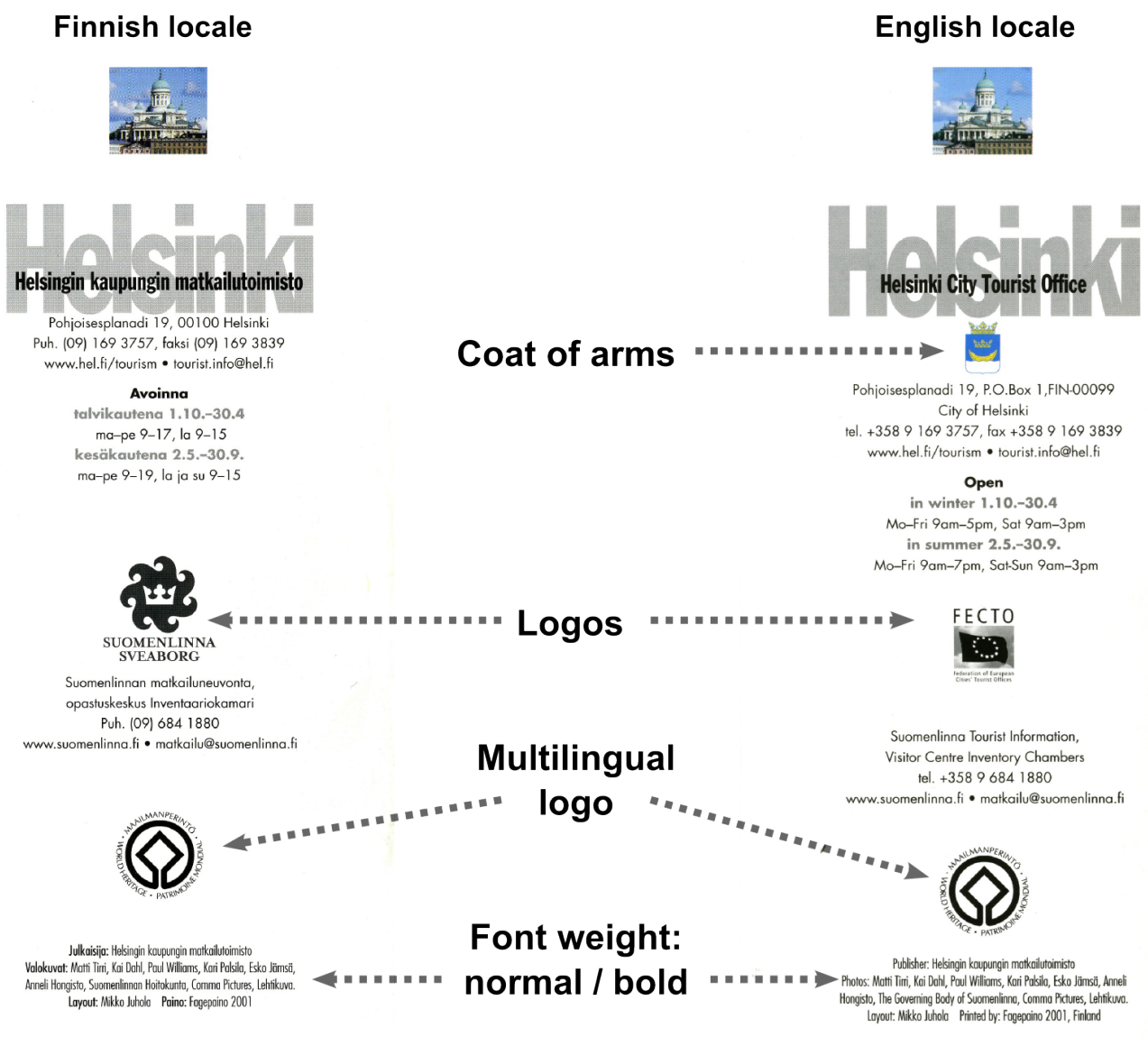

Figure 3: Back cover of Suomenlinna Maritime Fortress (2001)

Maritime Fortress brochure (see Figure 4). It was previously suggested in Subsection 2.1 that the process of translation is of highest priority in localisation. However, the failure to acknowledge the role of other semiotic resources results in a flawed design that is carried over to the target artefact. Firstly, the relationship between the symbol and its verbal restatement is based on their placement in the layout. The symbol for civil defence, a roundel with a triangle inside with the letters 'VSS' underneath it, is placed on the same level horizontally with the text 'Paloasema, ambulanssi', which stands for the fire and rescue service and emergency medical services, while the symbol of a cross, commonly associated with the emergency services is placed next to 'Väestönsuoja', which stands for civil defence. The four base units, consisting of the symbols and their restatements are incorrectly paired in the Finnish version. The order of the base units has been corrected in the localisation process by switching the place of the verbal base units (and producing the misspelled translation of 'Resque Station' [sic]), but the legend, 
Finnish locale

0

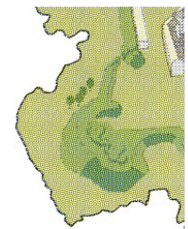

English locale

0

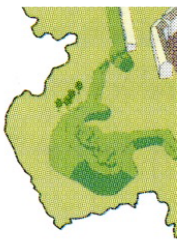

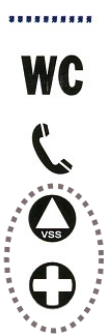

Pääreitti

Käymälä

Puhelinkioski

Paloasema, ambulanssi

Väestönsuoja

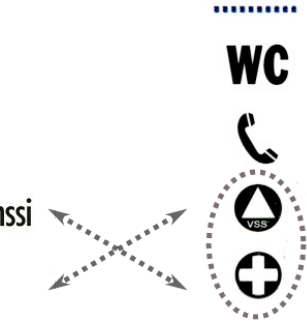

Main Route

Toilet

Telephone

Civil Defence Center

Resque Station

Figure 4: Map legend in Suomenlinna Maritime Fortress (2001)

realised in black and white, still uses the symbols specific to the Finnish locale, as indicated by the letters 'VSS' under the civil defence symbol.

It is questionable whether the Finnish symbol for civil defence is understandable to an international audience, especially when realised in black and white only. In these cases, the designers should strive for a maximal level of internationalisation and adopt a global approach to cultural adaptation (cf. Table 1) by employing the semiotic resource of colour. By adopting the international orange-blue variant of the civil defence symbol and the red cross on white background, both locales would be more efficient in communicating the intended message to the reader. As a conclusion, it seems that certain visual-verbal combinations such as maps and legends require particular attention in localisation, not only in including them in the localisation process, but also in negotiating the cline between localisation and internationalisation.

\subsection{Summer-Helsinki (2002)}

The Summer-Helsinki brochure, published in 2002, advertises both sights and activities within the city. These are described briefly and accompanied by practical information on the locations, costs and so on. Some of the locations are also depicted in photographs. In both locales, the verbal and visual elements are spatially organised using a grid, which is used to divide the page into columns and rows to aid in the placement of units. Figure 5 shows the content segmented into rows in the middle column, surrounded by margins on the left and right. 


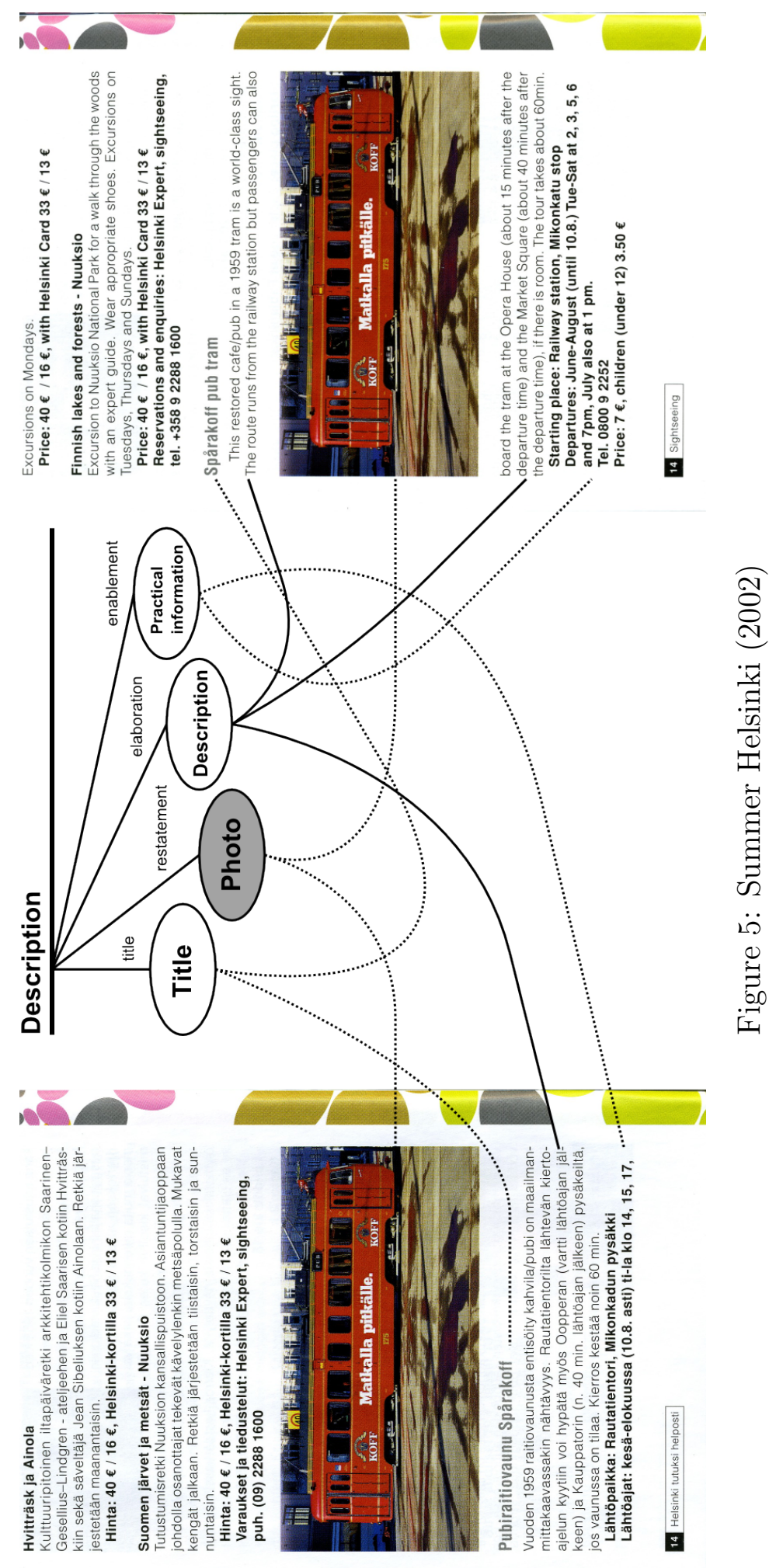


Bateman (2008, p. 76) describes the grid as a flexible design tool: it may be adjusted according to need and is not subject to strict constraints. In Figure 5, the placement of visual elements, such as the photograph and the illustration in the right margin, as well as the navigational element consisting of the page number and title retain static placement in the grid. The base units forming the verbal descriptions of the location are allowed to flow around the static elements and are thus flexible in their placement. However, due to alternating length of the verbal base units, resulting from structural factors such as grammatical features and word length, the English locale suffers from badly placed headings and body text. The photograph of the tram breaks the paragraph describing it: if the header were placed below the photograph, as in the Finnish brochure, it would push the practical information to the next page, thus causing a break in the rhetorical structure.

Schriver (1997, p. 343) introduces the term 'rhetorical cluster' to describe groups of visual or verbal units sharing the same communicative goal or function. In the GeM model, the rhetorical structure of a multimodal artefact is modelled using an application of the Rhetorical Structure Theory (hereafter RST; Mann \& Thompson 1988) to describe the relations holding between the rhetorical segments. Rhetorical structures often continue from one page to another in many artefacts (for example, in magazines and journals), however, in small-sized print media such as the tourist brochure the spatial grouping of description and practical information is user-friendly and therefore should be taken into consideration in localisation, as the example in Figure 5 shows. Design choices, such as the use of a smaller font size throughout the brochure or more importantly, the flexible positioning of non-verbal elements may offer solutions for retaining the original grouping and placement in the layout, thus providing better design solutions in the target locale. Implementing these design choices is not technically difficult, but they may be prevented by the modern work flow where such changes would require the co-operation of several persons: the copywriter, the translator and the art director. In many cases, the translator provides the raw text which is then placed in the localised version by those responsible for art direction; if the concept of multimodal localisation is developed further, the traditional role of a translator may be extended to cover the issues presented here.

\subsection{Winter Helsinki (2003)}

Winter Helsinki (2003) uses both language and image to advertise wintertime events and activities within the city. The descriptions typically follow a similar rhetorical structure, as shown in Figure 6 (see Table 4 for the rhetorical segments). The GeM model uses RST to describe the rhetorical organisation of a page, segmenting the verbal and visual elements into rhetorical units. Relations holding 
between the units are then defined according to the criteria defined in the RST relation definitions (see Mann \& Thompson (1988) for RST definitions and conventions). A relatively narrow selection of RST relations is used to persuade the reader to attend the advertised event: a TITLE segment enclosing a JOINT structure is followed by a brief description with ELABORATION, closing with ENABLEMENT segments that provide the practical information related to the event. Effectively, the rhetorical structure originating from the source locale has been preserved during the localisation process.
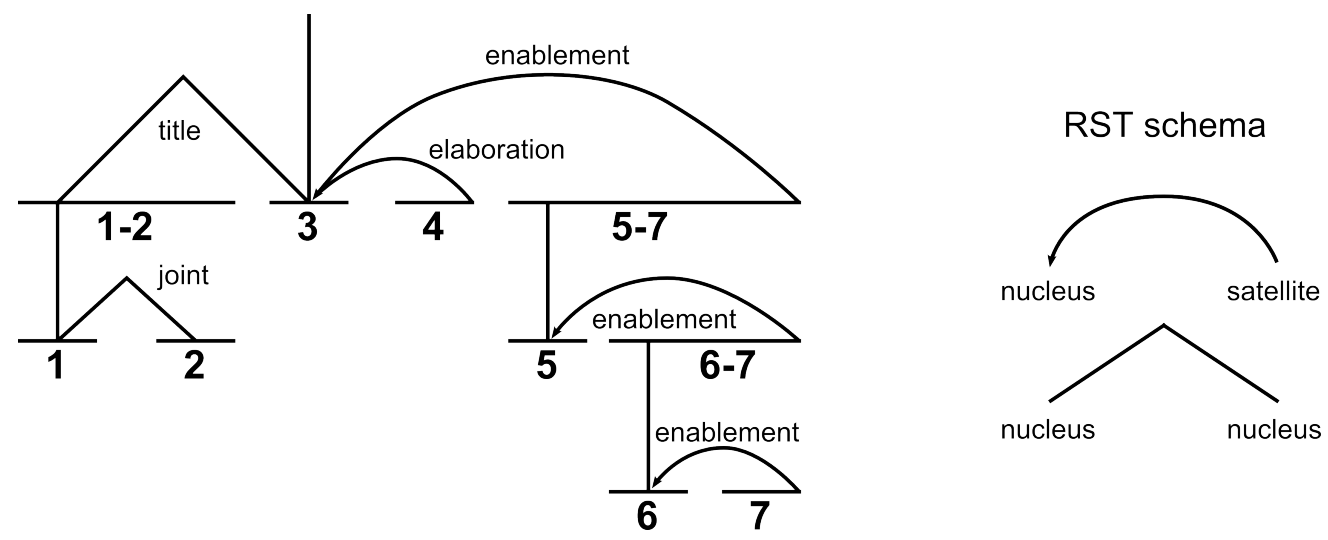

Figure 6: Rhetorical structure of the event descriptions in Winter Helsinki (2003)

The capability of the GeM model application of RST to aid in the localisation of linguistic elements is limited, as the minimal analytical unit defined in the model is an orthographic sentence, which prevents a close analysis of the linguistic features of the localised artefact. However, RST may be used to analyse the overall structure of the source artefact, the communicative goals it attempts to achieve and how, which may be then kept in mind when adapting the artefact into the target locale. Thomas (2009b, p. 306) approaches the use of RST in comparing packaging design in Taiwan and United Kingdom with caution, due to inherent ambiguity present in language and therefore also in rhetorical structure (Mann \& Thompson 1987, p. 30), suggesting that unarbitrated analyses with limited corpora cannot be used to draw conclusions on culture-specific rhetorical conventions.

It appears that in its current stage and before further development, multimodal RST as a part of the GeM model is best suited for critiquing document design by using it in connection with the other descriptive layers of the model. Cross-layer analyses between the layout and the rhetorical layers may be used to identify flawed designs in the source artefact, such as in the cases discussed in Subsections 5.1 and 5.2 ; the issues with design and localisation presented above are also connected to the rhetorical structure. However, limiting the application of RST to rhetorical analysis only does not provide significant benefits for localisation, as the brief 
Table 4: Rhetorical segments in the event descriptions

\begin{tabular}{|c|c|c|}
\hline $\begin{array}{l}\text { Rhetorical } \\
\text { segment } \\
\text { number }\end{array}$ & Finnish & English \\
\hline 1 & $20 .-23.11 .2003$ & $20 .-23.11 .2003$ \\
\hline 2 & AVANTO-FESTIVAALI & AVANTO FESTIVAL \\
\hline 3 & $\begin{array}{l}\text { Pohjoismaiden suurin } \\
\text { vuosittainen mediafesti- } \\
\text { vaali, jonka kansainvälinen } \\
\text { ohjelma esittelee kokeel- } \\
\text { lisen elokuvan ja musiikin } \\
\text { uusimpia virtauksia ja } \\
\text { Suomessa tuntemattomia } \\
\text { klassikoita. }\end{array}$ & $\begin{array}{l}\text { The largest annual media } \\
\text { festival in the Nordic re- } \\
\text { gion, the mainly interna- } \\
\text { tional programme presents } \\
\text { the latest trends in exper- } \\
\text { imental film and music as } \\
\text { well as classic works seldom } \\
\text { seen in Finland. }\end{array}$ \\
\hline 4 & $\begin{array}{l}\text { Teemana on tällä kertaa } \\
\text { avantgarde-suuntaus sekä } \\
\text { underground-taide. }\end{array}$ & $\begin{array}{l}\text { This year's theme is the } \\
\text { avant-garde and under- } \\
\text { ground art. }\end{array}$ \\
\hline 5 & $\begin{array}{l}\text { Useita esityspaikkoja, mm. } \\
\text { Nykytaiteen museo Kiasma, } \\
\text { Mannerheiminaukio } 2\end{array}$ & $\begin{array}{l}\text { Several venues, including } \\
\text { the Museum of Contempo- } \\
\text { rary Art, Kiasma, Manner- } \\
\text { heiminaukio } 2\end{array}$ \\
\hline 6 & $\begin{array}{l}\text { Liput: paikan päältä en- } \\
\text { nakkoon tai ovelta }\end{array}$ & $\begin{array}{l}\text { Tickets: in advance or at } \\
\text { the door from the venue }\end{array}$ \\
\hline 7 & $\begin{array}{l}\text { Hinta: Kiasma } 6 / 5 € \text { eloku- } \\
\text { vat, } 10 / 8 € \text { tai } 12 / 10 € \\
\text { live-esitykset (sis. museon } \\
\text { pääsymaksun), festivaali- } \\
\text { passi } 67 €\end{array}$ & $\begin{array}{l}\text { Prices: Kiasma } 6 / 5 € \text {, } \\
10 / 8 € \text { or } 12 / 10 € \text { live } \\
\text { performances (included } \\
\text { in museum entrance fee), } \\
\text { festival pass } 67 €\end{array}$ \\
\hline
\end{tabular}

example shown in this subsection exemplifies. The main advantage of multimodal analysis for localisation is in combining multiple layers of analysis to identify any possible aspects of the design that may be challenging to localise, thus providing a tool for critique, which enables the process to produce designs that communicate efficiently.

\subsection{Helsinki Your Way (2006)}

The newest brochure included in the material, Helsinki Your Way (2006), is in many aspects more complex in its design than its older counterparts: it contains 
localised advertisements that occupy their own layout areas and thus have their own rhetorical structure, some locale-specific content, and a complex navigation structure. As the issues related to layout and rhetorical structure have been discussed in the previous subsections, the focus of this subsection will be on navigation structures, their realisation using multiple semiotic resources and their role in the process of localisation.

Bateman (2008, p. 175-6) introduces the concept of 'page-flow', which describes how text, graphics, photographs, maps, diagrams and headers all contribute to the overall communicative goal; they interact with each other and use the two-dimensional space available on a page to organise themselves rhetorically. Page-flow may also be seen as continuous: in many print media artefacts, similar spatial placement of the verbal and visual elements benefits the readers as they do not have to accustom themselves to novel layout designs after every turn of the page. However, the growing amount of content has resulted in the emergence of navigation structures in print media to enable the readers to cope with the increased content.

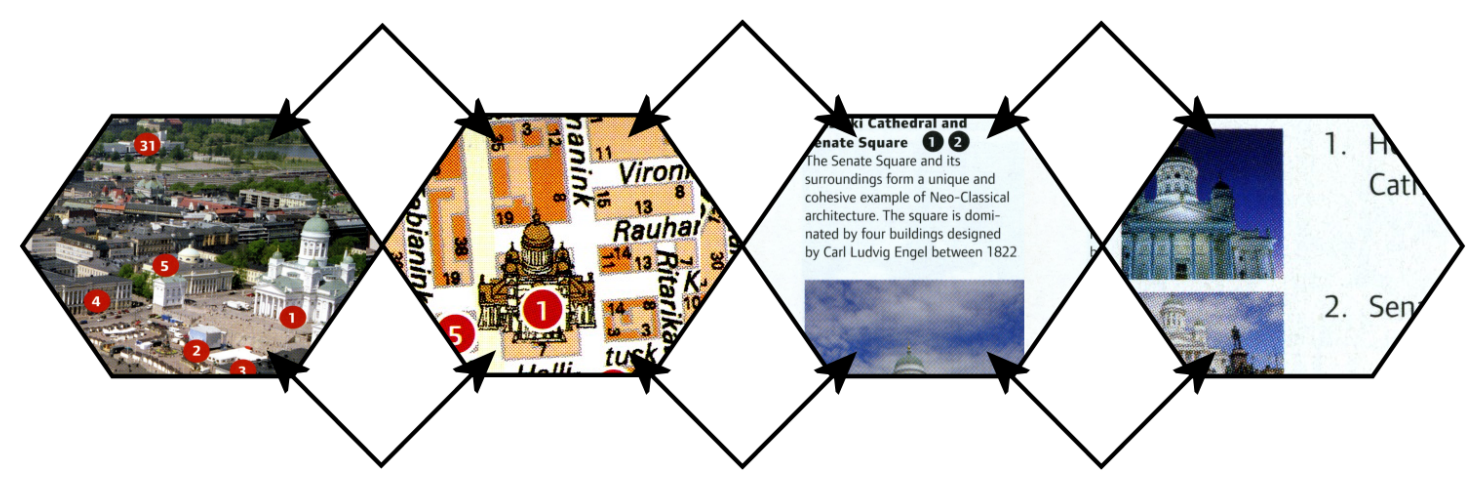

Figure 7: Navigation structure in Helsinki Your Way (2006)

The two central concepts in the navigation layer of the GeM model are 'pointer' and 'entry'. Pointers and entries, composed of base units, form the starting and ending points of a navigation structure; they may be either explicit, in cases such as 'see page 5', or implicit, using two visual elements with similar realisations to create a navigation structure. Latter examples may be found from maps and the verbal descriptions connected to it. Figure 7 shows the use of an explicit navigation structure in the Helsinki Your Way brochure. The explicit numbering is used to establish connections within the page-flow, regardless of the semiotic resources used to realise the content, creating a two-way navigation structure, where the numbering acts as both the pointer and the entry. The descriptions of the locations are identified using the same numbers in the map and an aerial photograph of the city, complemented by a collection of smaller photographs. 
From the perspective of localisation, the example above is relatively simple to adapt to the target locale, as it is based on numbering. The overall design itself is particularly efficient, as it describes the locations using multiple semiotic resources and their realisations: maps for geographical information and photographs for a visual description. The navigation structure and page-flow enable this type of description, as the constraints set by the distribution and use do not allow the use of pages with sufficient semiotic space for the inclusion of all of the information. However, as the number of pointers and entries grows, increased attention has to be paid in localisation in order to adapt the navigation structure. The flexible placement of elements (such as in Subsection 5.2) require verifying each explicit pointer. However, in general, both page-flow and the common navigation structures are well-established conventions, which suggest that significant variation between different locales is unlikely.

\section{Conclusion and implications}

The tourist brochures produced by the city of Helsinki and analysed as a part of this study, although limited in number, showed a variety of strategies in adapting the brochures from Finnish into English. In most cases, the producers had opted for straightforward translation. However, the multimodal analysis using the GeM model showed that there are certain factors that need to be accounted for if efficient communication is to be preserved during the localisation process. These factors are intertwined: changing one aspect in the source artefact such as the layout structure, may affect the rhetorical structure of the brochure in the target artefact, as was the case with the example discussed in Section 5.2. Increased attention should be paid to these factors, as well as to visual communication in general. Balancing the degree of localisation and its counterpoint, internationalisation, is of importance if the communicative purposes defined in the source artefact are to be retained in the localised version.

From a practical perspective, it appears that the concept of localisation could be extended to print media and be reworked into a multimodal process providing a practical application for the theories of multimodality. Multimodal analysis offers concrete methods for analysing how the more abstract concepts discussed in visual communication and design research are realised, which may be used to provide solutions for both design and localisation, as this chapter has attempted to show. It seems that although the methods exist, even the limited sample included in this study shows that other semiotic resources besides language are somewhat neglected in the localisation process. Several possible reasons for this were presented: the lack of time and resources, the current division of work and the attitudes towards the original artefact, which prevent its extensive modification and adaptation. 
Thus, the multimodal localisation of print media might also require redefining the roles by combining the role of a translator and an art director.

The theories of multimodal meaning-making, in turn, appear to require increased reliability in analysis in order to support the decisions made in design and localisation. The development of systematic frameworks such as the GeM model needs to be complemented by analytical tools which allow the creation of largescale corpora for making hypotheses and verifying them. Several frameworks have been and are being currently developed (see e.g. Baldry \& Thibault 2005, Bateman 2008, O'Halloran 2008) but there appears to be little dialogue between them. A common ground needs to be found before the interest of the localisation industry and the wider audience may be raised.

\section{References}

Baldry, A. P. \& Thibault, P. J. (2005), Multimodal transcription and text analysis, Equinox, London.

Barthes, R. (1957/1973), Mythologies, Paladin, London. Translated by Annette Lavers.

Bateman, J. A. (2008), Multimodality and Genre: A Foundation for the Systematic Analysis of Multimodal Documents, Palgrave Macmillan, London.

Bateman, J. A., Delin, J. L. \& Henschel, R. (2004), Multimodality and empiricism: preparing for a corpus-based approach to the study of multimodal meaning-making, in E. Ventola, C. Charles \& M. Kaltenbacher, eds, 'Perspectives on Multimodality', Benjamins, Amsterdam, pp. 65-89.

Bateman, J. A., Delin, J. L. \& Henschel, R. (2007), Mapping the multimodal genres of traditional and electronic newspapers, in T. D. Royce \& W. L. Bowcher, eds, 'New Directions in the Analysis of Multimodal Discourse', Lawrence Erlbaum, Mahwah, NJ, pp. 147-172.

Cheong, Y. Y. (2004), The construal of ideational meaning in print advertisements, in K. L. O'Halloran, ed., 'Multimodal Discourse Analysis: Systemic Functional Perspectives', Continuum, London, pp. 163-195.

Culler, J. (1988), Framing the Sign: Criticism and its Institutions, Blackwell, Oxford.

Delin, J., Bateman, J. A. \& Allen, P. (2003), 'A model of genre in document layout', Information Design Journal 11(1), 54-66.

Delin, J. L. \& Bateman, J. A. (2002), 'Describing and critiquing multimodal documents', Document Design 3(2), 140-155.

Esselink, B. (2000), A Practical Guide to Localization, Benjamins, Amsterdam.

Halliday, M. A. K. (1978), Language as a Social Semiotic: The Social Interpretation of Language and Meaning, Arnold, London.

Halliday, M. A. K. \& Matthiessen, C. M. I. M. (2004), An Introduction to Functional Grammar, third edn, Arnold, London.

Henschel, R. (2003), GeM Annotation Manual, second edn, University of Bremen, University of Stirling.

Hiippala, T. (2007), Helsinki: A multisemiotic analysis of tourist brochures, Master's thesis, University of Helsinki.

Hopearuoho, A. \& Ventola, E. (2009), Multisemiotic marketing and advertising: Globalization 
versus localization and the media, in E. Ventola \& A. J. Guijarro, eds, 'The World Told and the World Shown: Multisemiotic Issues', Palgrave, London, pp. 183-204.

Jones, C. \& Ventola, E., eds (2008), From Language to Multimodality: New Developments in the Study of Ideational Meaning, Equinox, London.

Kaltenbacher, M. (2004), 'Perspectives on multimodality: from the early beginnings to the state of the art', Information Design Journal + Document Design 12(3), 190-207.

Kostelnick, C. (1995), 'Cultural adaptation and information design: Two contrasting views', IEEE Transactions on Professional Communication 38(4), 182-196.

Kostelnick, C. \& Hassett, M. (2003), Shaping Information: The Rhetoric of Visual Conventions, Southern Illinois University Press, Carbondale.

Kress, G. \& van Leeuwen, T. (1996), Reading Images: The Grammar of Visual Design, Routledge, London.

Kress, G. \& van Leeuwen, T. (2001), Multimodal Discourse: The Modes and Media of Contemporary Communication, Arnold, London.

Laitinen, K. (1998), The rise of finnish-language literature, 1860-1916, in G. C. Schoolfield, ed., 'A History of Finland's Literature', University of Nebraska Press, Lincoln, pp. 64-144.

Machin, D. (2004), 'Building the world's visual language: The increasing global importance of image banks in corporate media', Visual Communication 3(3), 316-336.

Mann, W. C. \& Thompson, S. A. (1987), Rhetorical Structure Theory: A theory of text organization, Technical report. ISI/RS-87-190, University of Southern California, Information Sciences Institute (ISI).

Mann, W. C. \& Thompson, S. A. (1988), 'Rhetorical Structure Theory: Toward a functional theory of text organization', Text 8(3), 243-281.

Martinec, R. (2003), 'The social semiotics of text and image in [j]apanese and [e]nglish software manuals and other procedures', Social Semiotics 13(1), 43-69.

O'Halloran, K. L. (2005), Mathematical Discourse: Language, Symbolism and Visual Images, Continuum, London.

O'Halloran, K. L. (2008), 'Systemic functional-multimodal discourse analysis (SF-MDA): Constructing ideational meaning using language and visual imagery', Visual Communication 7(4), 443-475.

O'Halloran, K. L., ed. (2004), Multimodal Discourse Analysis: Systemic Functional Perspectives, Continuum, London.

O'Toole, M. (1994), The Language of Displayed Art, Leicester University Press, London.

Schriver, K. A. (1997), Dynamics in Document Design: Creating Text for Readers, Wiley, New York.

Stöckl, H. (2005), 'Typography: body and dress of a text - a signing mode between language and image', Visual Communication 4(2), 210-214.

Thomas, M. (2007), Querying multimodal annotation: A concordancer for GeM, in 'Proceedings of the Linguistic Annotation Workshop', Association for Computational Linguistics, Prague, Czech Republic, pp. 57-60.

URL: http://www.aclweb.org/anthology/W/W07/W07-1510

Thomas, M. (2009a), Developing multimodal texture, in E. Ventola \& A. J. Guijarro, eds, 'The World Told and the World Shown: Multisemiotic Issues', Palgrave, London, pp. 39-55.

Thomas, M. (2009b), Localizing pack messages: A framework for corpus-based cross-cultural multimodal analysis, $\mathrm{PhD}$ thesis, University of Leeds.

van Leeuwen, T. (2005), 'Typographic meaning', Visual Communication 4(2), 137-143.

Ventola, E., Charles, C. \& Kaltenbacher, M., eds (2004), Perspectives on Multimodality, Benjamins, Amsterdam. 
Ventola, E. \& Guijarro, A. J., eds (2009), The World Told and the World Shown: Multisemiotic Issues, Palgrave, London. 